\title{
Potential impact and non-target effects of Gallerucida bifasciata (Coleoptera: Chrysomelidae), a candidate biological control agent for Fallopia japonica
}

\author{
Yangzhou Wang ${ }^{\text {a,b,c }}$, John R.U. Wilson ${ }^{\text {d,e }}$, Jun Zhang a,f , Jialiang Zhang ${ }^{\text {a,g }}$, Jianqing Ding a,g,* \\ ${ }^{a}$ Wuhan Botanical Garden/Institute, Chinese Academy of Sciences, Wuhan, Hubei 430074, China \\ ${ }^{\mathrm{b}}$ Institute of Plant Protection, Jilin Academy of Agricultural Sciences, Changchun, Jilin, China \\ ' Graduate School of the Chinese Academy of Sciences, Beijing 100049, China \\ ${ }^{\mathrm{d}}$ South African National Biodiversity Institute, Kirstenbosch National Botanical Gardens, Claremont, South Africa \\ ${ }^{\mathrm{e}}$ DST-NRF Centre of Excellence for Invasion Biology, Department of Botany E Zoology, Stellenbosch University, South Africa \\ ${ }^{\mathrm{f}}$ Department of Plant Protection, Huazhong Agricultural University, Wuhan, Hubei 430000, China \\ ${ }^{\mathrm{g}}$ Key Laboratory of Aquatic Botany and Watershed Ecology, Chinese Academy of Sciences, Wuhan, Hubei 430074, China
}

\section{A R T I C L E I N F O}

\section{Article history:}

Received 30 August 2009

Accepted 3 December 2009

Available online 16 December 2009

\section{Keywords:}

Risk assessment

Control efficacy

Invasive plants

Natural enemy

Specialist insect

Larval density dependence

\begin{abstract}
A B S T R A C T
A pre-release evaluation of a potential biological control agent is designed to estimate the impact the agent will have on the target in the introduced range, and whether the agent poses an acceptable level of risk to biodiversity. Here, we present an evaluation of the Asian leaf-beetle, Gallerucida bifasciata, a potential biological control agent for Japanese knotweed, Fallopia japonica. First we tested the impact of different larval and adult densities on the plant under laboratory conditions. After six weeks, the biomass of $F$. japonica was $15 \%$ or $28 \%$ that of control plants if larvae or adults were added, with levels of damage plateauing quickly with increasing insects densities. High fecundity and larval density dependence means that this agent could substantially and quickly suppress plant growth, although this damage only occurs early in the season, allowing F. japonica time to compensate. Second, following on from general host-specificity trials, we investigated potential non-target effects on the commercially important plant buckwheat, Fagopyrum esculentum, in more depth. The leaf-beetle showed some minor adult feeding on F. esculentum in choice trials, and in no-choice trials the leaf-beetle was able to complete its life cycle and sustain a population on F. esculentum, albeit causing lower levels of damage than on $F$. japonica. This suggests that if the beetle dispersed to areas where $F$. japonica is not present, it might colonise $F$. esculentum. Therefore, despite potentially being an effective agent, that the risk of non-target feeding is unacceptably high.
\end{abstract}

(c) 2009 Elsevier Inc. All rights reserved.

\section{Introduction}

When selecting biological control agents, pre-release studies in the native range are of critical importance in supplementing hostrange tests (McClay and Balciunas, 2005). Pre-release impact studies can be used to measure the effect of herbivory on the growth and reproduction of the target weed using a realistic range of insect densities. If an agent is host-specific, maintains a large population, but does not significantly reduce plant population sizes then there might be significant indirect non-target effects in ecosystems (Pearson and Callaway, 2003). Moreover, if a normally host-specific agent reaches very high population densities that cannot be sustained by the target plant there might be undesirable non-target effects (Briese, 2005; Sheppard et al., 2005).

\footnotetext{
* Corresponding author. Address: Invasion Ecology and Biocontrol Lab, Wuhan Botanical Institute/Wuhan Botanical Garden, Chinese Academy of Sciences, Wuhan, Hubei 430074, China. Fax: +86 2787510251.

E-mail address: dingjianqing@yahoo.com (J. Ding).
}

Assessments in the native range can also be very effective in assessing the risk of potential biological control agents to non-targets as they can be carried out under more natural conditions (Louda, 1998; Louda et al., 2005; Ding et al., 2007). For example, a wider host-range is often seen under no-choice laboratory conditions than is observed in the field or post-release (Cameron and Walker, 1997; Morehead and Feener, 2000; Haye et al., 2005), and so semi-field studies are important in cases where the results of preliminary host-range testing are inconclusive.

Native to China and Japan, Japanese knotweed, Fallopia japonica (Houttuyn) Ronse Decraee, was introduced into Europe and North America in the 19th century, where it has arguably become one of the most problematic invasive weeds (Beerling et al., 1994; van Driesche et al., 2002). Fallopia japonica grows in various habitats, but prefers moist environments, e.g. riparian habitats (Bailey, 2003). At high densities, $F$. japonica can out-compete other plant species in the community (Barney, 2006), thereby reducing diversity (van Driesche et al., 2002; Maerz et al., 2005). Given the difficulty of managing F. japonica, classical biological control is seen as the only long-term solution. 
Gallerucida bifasciata Motschulsky (Coleoptera: Chrysomelidae), is a candidate biological control agent native to East Asia. Previous host-range multiple choice tests found that adults of G. bifasciata display strong feeding and ovipositional preferences for three species native to China, F. japonica, Persicaria perfoliata (L.) H. Gross, and Fallopia multiflorum Thunb (Wang et al., 2008). Furthermore, in laboratory no-choice tests, G. bifasciata fed and completed development on F. japonica, F. multiflorum, Persicaria perfoliata, Rumex acetosa L., Fagopyrum dibotrys (D. Don) Hara, Polygonum runcinatum Buch.-Ham. ex D. Don var. sinense Hemsl., and importantly buckwheat, Fagopyrum esculentum Moench. As F. esculentum is an important economic crop in the US (Wang et al., 2008), that is grown in areas invaded by $F$. japonica (USDA, 2009), further risk assessment of the introduction of $G$. bifasciata on $F$. esculentum is necessary. In this paper we aim to assess the impact and likely population dynamics of G. bifasciata on F. esculentum and, in the light of this potential impact, whether G. bifasciata poses an acceptable risk to $F$. esculentum production.

\section{Materials and methods}

\subsection{Gallerucida bifasciata}

Gallerucida bifasciata is a species complex found throughout China (Zhang Lijie, personal communications). Across the complex there is variation in host-use, and most prominently colouration. The population used in this experiment is a yellow strain from $\mathrm{Wu}-$ han $\left(30^{\circ} 32^{\prime} 37^{\prime \prime} \mathrm{N} ; 114^{\circ} 24^{\prime} 53^{\prime \prime} \mathrm{E}\right)$, the same strain used in previous host-range tests (Wang et al., 2008). In this region leaf-beetle populations are univoltine. Adults emerge from overwintering, copulate, and oviposit in late March. Eggs hatch after about 7 days, the larvae take around 20 days to develop, and pupation is about a week (Wang et al., 2008). Adults emerge in late May to early June and enter a combined aestivation then hibernation until the following spring, although in cooler areas the beetle can undergo another generation in the autumn. The larvae and adults feed on the leaves of $F$. japonica and can cause considerable damage through canopy defoliation.

\subsection{Impact of G. bifasciata feeding on F. japonica (experiment 1)}

All feeding experiments were performed under standard greenhouse conditions: $20-30{ }^{\circ} \mathrm{C}, 60-90 \% \mathrm{RH}$, and a 14 -h photoperiod. Roots of $F$. japonica were collected from naturally occurring populations and were cut into segments each with only one radical bud. Segments were planted in pots $(18 \mathrm{~cm}$ in diameter by $16 \mathrm{~cm}$ deep) using local topsoil that was carefully checked for insects. After about 30 days, similar sized plants with eight leaves were selected for the experiment. All plants, including those used as controls, were placed in nylon-mesh cages $(20 \mathrm{~cm}$ wide by $20 \mathrm{~cm}$ long by $50 \mathrm{~cm}$ tall).

Overwintering adults of $G$. bifasciata were collected in the field in late March, 2008 in Wuhan, Hubei Province, and were kept in culture on $F$. japonica in cages ( $1 \mathrm{~m}$ wide by $1 \mathrm{~m}$ long by $1 \mathrm{~m}$ tall). For the adult treatment, adults were released onto the test plants at densities of $0,1,2$ and four adults per plant (the sex of adults was not determined, but no larvae were subsequently observed in this treatment). For the larval treatment, eggs were collected from soil in the cages used for culturing insects and put into separate containers in order to monitor emergence. Emerging neonates were then transferred onto the leaves of test plants with a fine-tip paintbrush. Densities of $0,2,5,10$ and 20 larvae per plant were kept constant throughout the experiment by replacing any dead larvae with fresh larvae of a similar age/size. All the tests were started on the same day and treatments were replicated 10 times.
The experiment continued for approximately 23 days after inoculation, until pupation or the adults aestivated. The surviving test plants were removed, cleaned of soil, then oven dried at $80^{\circ} \mathrm{C}$ for $48 \mathrm{~h}$. Above- and below-ground portions were weighed separately.

\subsection{Risk assessment of G. bifasciata (experiment 2)}

This experiment was performed in an outdoor garden at the Wuhan Botanical Garden, Chinese Academy of Sciences, Wuhan, Hubei Province in central China. Roots of $F$. japonica were collected from wild populations in February 2008, and were then cultured in the greenhouse until sprouting. Seeds of $F$. esculentum were sowed in March, 2008. For each species, plants with similar leaf areas were chosen and planted in pots $(18 \mathrm{~cm}$ in diameter by $16 \mathrm{~cm}$ deep) using cleaned locally collected soil. The soil in the experimental area was turned over and nylon-meshed cages $(1 \mathrm{~m}$ wide by $1 \mathrm{~m}$ long by $1 \mathrm{~m}$ tall) were buried $10 \mathrm{~cm}$ into the ground (sufficient to prevent movement of adults or larvae into or out of the cages). Each cage was assigned to a treatment of plant type and adult density. Plants were added to the cages in three treatments to give a range of choice and no-choice tests ( 12 pots $F$. esculentum per cage; six pots of $F$. japonica; or a mix of six pots of $F$. japonica and six pots of $F$. esculentum per cage). Adults were then added to the cages at two densities approximating field densities seen in G. bifasciata in mid-April, 2008 ( 2 or 4 mating pairs per cage). Each treatment was replicated five times. Thus, a total of 30 cages ( 3 choices of plant $\times 2$ adult densities $\times 5$ replicates) were used.

Following the release of adults on 8 April 2008, plant damage and number of larvae were assessed every three days. Plant damage (the combined leaf feeding of adults and larvae) was assessed by tracing damaged leaves onto gridded graph paper. This meant that the total area of leaf consumed could be determined for each treatment. By the end of the experiment (mid-June) no larvae or adults were left on the plants. To find the number of aestivating adults per treatment, we dug up $10 \mathrm{~cm}$ of soil under each cage and searched it for insects. To look at the effect of plant identity on adult weight, we weighed 15 male and 15 female aestivating adults from both no-choice tests (Sartorius Balance, accuracy: $0.0001 \mathrm{~g}$ ).

\subsection{Statistical analysis}

For experiment 1, data on the biomass at the end of the experiment were log-transformed (as biomass is the result of variation in growth rates). The effects of host-plant and number of insects added on final biomass were analysed using ANOVAs. To examine whether insect damage saturated, we also tested models where high insect densities were grouped using AIC and F-tests.

Regarding the data from experiment 2, we analysed factors affecting the total leaf area consumed. The effect of host-plant and initial adult densities on the peak larval numbers was also tested using ANOVAs, and the overall patterns were confirmed using general linear repeated measures model. The effects of host-plant and sex on the log-transformed mass of adult beetles were also tested using a two-way ANOVA.

Effect sizes were calculated throughout using the parameter estimates obtained.

\section{Results}

\subsection{Impact of G. bifasciata feeding on F. japonica (experiment 1)}

Larval feeding on $F$. japonica resulted in much less above- and below-ground biomass (above-ground: $F_{4,45}=103, p<0.01$; below-ground: $F_{4,45}=481, p<0.01$; Fig. 1 ). The data suggest there 

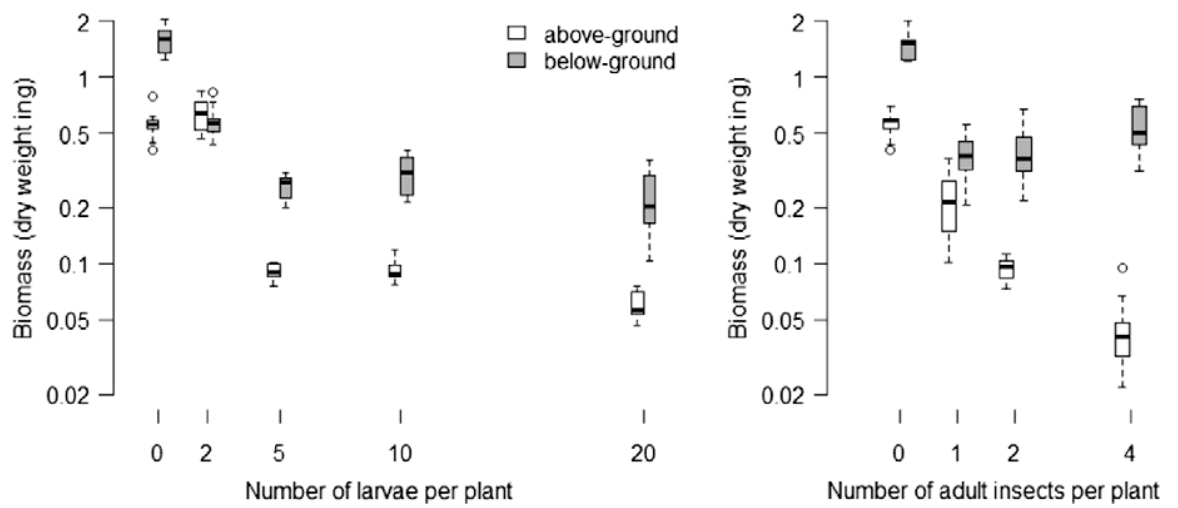

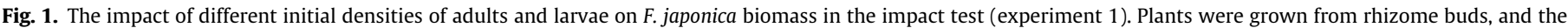

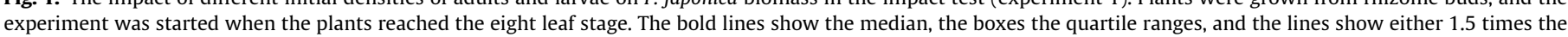
interquartile range or the point furthest from the median, whichever is less. Outliers outside this range are plotted individually.

is little additional effect on the plant if more than five larvae are added (although the AIC of a model including all larval densities as separate factor levels is less than a model where larval densities of five and above are grouped, -18.9 as opposed to -4.0 ). When there were five or more larvae, total biomass was $15 \%$ that of control plants (95\% C.I.: $10-24 \%$ ). Indeed, plants were completely defoliated in the treatments containing 10 and 20 larvae per plant in only three to four days following inoculation. Larvae numbers were also negatively correlated to the number of root buds.

The addition of adults had a similar, but slightly smaller, effect on the plants (above-ground biomass: $F_{3,39}=120, p<0.01$; belowground: $F_{3,36}=47.9, p<0.01$; Fig. 1 ). And again, the effect of adding adults plateaued at low densities, with only relatively small additional reductions in above-ground biomass above one adult per plant. When there was at least one adult the total biomass was $28 \%$ that of control plants (95\% C.I.: $14-54 \%$ ). Interestingly, the below-ground biomass in the high density treatment ( 4 adults) was higher than that in the low density treatments (1 adult) (Fig. 1). Plants were completely defoliated after three to four days if four adults were added per plant.

\subsection{Risk assessment of G. bifasciata (experiment 2)}

\subsubsection{Feeding damage}

Gallerucida bifasciata fed on $F$. esculentum in both choice and non-choice trials. However, in choice tests the total area consumed of $F$. esculentum over the entire study period was $1.7 \%$ that of $F$. japonica (95\% C.I.: 1.1-2.6\%); and in no-choice tests it was $45.7 \%$ (95\% C.I.: 40.6-51.8\%) (see Table 1 ).
On F. esculentum the initial number of pairs of beetles added had no effect on the feeding damage $\left(F_{2,18}=0.60, p=0.56\right)$, but feeding was markedly greater in the no-choice than choice tests (Table 1a and Fig. S1). On F. japonica feeding rates were broadly similar across all treatments (Table $1 \mathrm{~b}$ and Fig. S1). Feeding was slightly greater in choice tests when initial beetle density was four (as opposed two), but in non-choice tests the opposite was found. Generally with greater initial densities of adults, feeding was greater earlier in the experiment, but there seemed to be a limit to the total amount that was consumed (Fig. S1).

\subsubsection{Larval numbers}

Larvae numbers in the different treatments showed similar trends throughout the experiment (Fig. 2) and always peaked at 19 days. In the no-choice test, the peak number of larvae found on $F$. esculentum was roughly half that on $F$. japonica, while in the choice tests no larvae were found on $F$. esculentum (Fig. 2). This suggests a high preference for the target weed. The peak number of larvae found on $F$. japonica was slightly higher in the choice than the no-choice test $\left[F_{1,17}=4.8, p=0.043,3.5 \%\right.$ more (95\% C.I.: $0.1-$ $7.1 \%)]$. The peak number of larvae found on $F$. japonica plants with four pairs per cage was also more than if only two pairs were added, but not nearly close to double $\left[F_{1,17}=130, p<0.01,17.5 \%\right.$ more (95\% C.I.: $14.3-20.7 \%$ ), a size effect that was the same for both choice and no-choice treatments]. However, the initial number of pairs of beetles did not significantly affect the peak larval numbers observed on $F$. esculentum in no-choice tests $\left(F_{1,8}=3.00, p=0.12\right)$. These observations seem to hold at all sample dates (Fig. 2), and an analysis using general linear model repeated measures analysis of variance came to the same qualitative conclusions.

Table 1

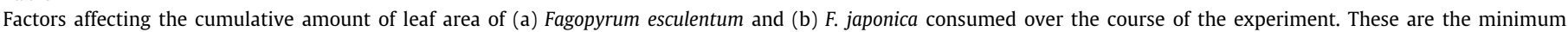

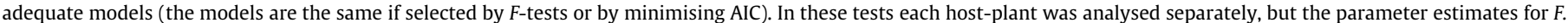
japonica are consistently (and significantly) much larger than for Fagopyrum esculentum, see text for more details.

\begin{tabular}{|c|c|c|c|c|}
\hline Parameter & Estimate & Standard error & $t$-Value & p-Value \\
\hline \multicolumn{5}{|c|}{ (a) Log (area of Fagopyrum esculentum eaten $\left.\left(\mathrm{cm}^{2}\right)\right) \sim$ type (choice or no-choice) } \\
\hline Intercept (choice test) & 1.58 & 0.668 & 23.7 & $<0.001$ \\
\hline No-choice test & +3.21 & 0.0944 & 34.0 & $<0.001$ \\
\hline \multicolumn{5}{|c|}{ Residual standard error: 0.211 on 18 d.f.; $r^{2}=0.985 ; F_{1,18}=1150, p<0.001$} \\
\hline \multicolumn{5}{|c|}{ (b) $\log \left(\right.$ area of $F$. japonica eaten $\left.\left(\mathrm{cm}^{2}\right)\right) \sim$ Number of adult weevils added initially (two pairs or four pairs) $*$ test (choice or no-choice) } \\
\hline Intercept (choice test, two pairs of beetles) & 5.33 & 0.0293 & 182 & $<0.001$ \\
\hline No-choice test & +0.137 & 0.0414 & 3.30 & 0.0045 \\
\hline Four pairs of beetles & +0.636 & 0.0414 & 15.4 & $<0.001$ \\
\hline No-choice test: four pairs of beetles & -0.435 & 0.0586 & -7.415 & $<0.001$ \\
\hline
\end{tabular}



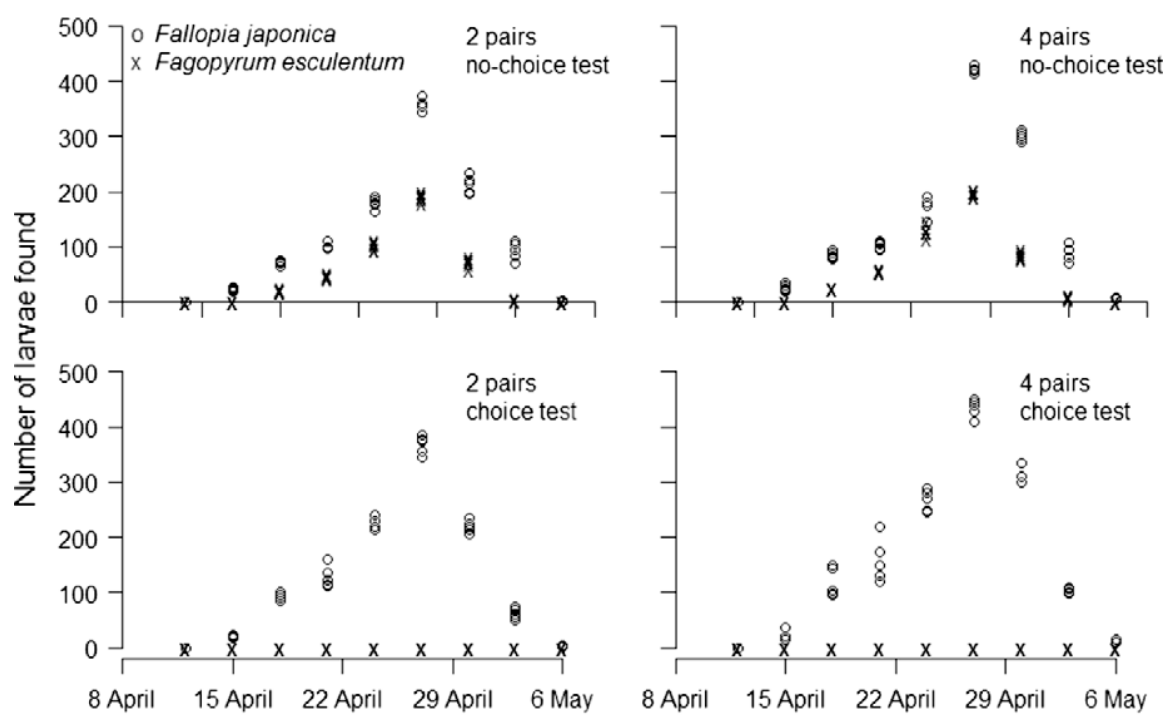

Date (the experiment was conducted in 2008)

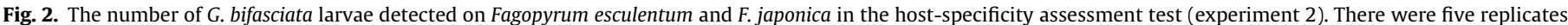
per treatment.

\subsubsection{Adult numbers}

At the end of the experiment, adults were found in all treatments. When analysed together final adult numbers were significantly affected by an interaction between treatment and number of initial adults $\left(F_{5,24}=95.7, p<0.01\right)$. Interestingly there was no significant difference in adult numbers emerging from no-choice cages containing $F$. japonica and no-choice cages containing $F$. esculentum (despite the marked differences in larval numbers) (Figs. 2 and 3). Moreover while in the choice tests, the number of adults at the start of the experiment had no significant effect on the number of adults at the end of the experiment, in both no-choice tests the number of final adults approximately doubled when initial adult numbers doubled (Table 1 and Fig. 2).

\subsubsection{The mass of adults on F. esculentum and F. japonica}

Both sex and host-plant significantly affected the individual mass of adult leaf-beetles collected, but there was no interaction between sex and host-plant $\left(F_{2,57}=39.3, p<0.01\right.$, Fig. 4$)$. Females were around $20 \%(13-27 \%, 95 \%$ C.I.s) heavier than males, and adults on F. esculentum were 35\% (28-43\%, 95\% C.I.s) heavier than those on F. japonica.

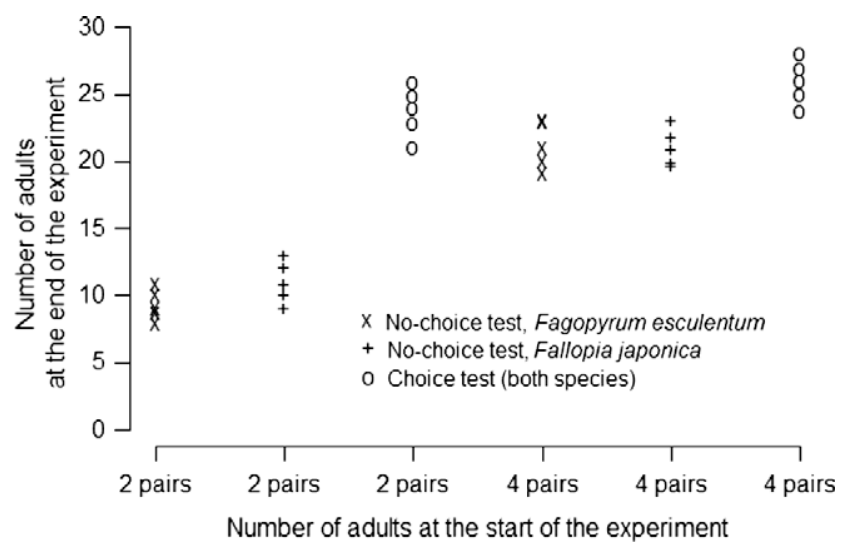

Fig. 3. The effect of treatment and initial adult density on the final number of adult leaf-beetles found in the host-specificity assessment test (experiment 2). Note all original values are integers, but a small amount of variation is added to prevent overplotting.

\section{Discussion}

To be able to predict the eventual impact of a herbivore on a plant, data are required both on the type and severity of damage caused, and on what factors are likely to regulate the population dynamics of the agent in its introduced range (e.g. Wilson et al., 2006). Ideally, an agent should be highly damaging and not show boom and bust population cycles (McClay and Balciunas, 2005).

In the experiments, both larvae and adults were very effective in defoliating plants. The impact on plants with established root systems remains to be seen, but this agent might be expected to effectively prevent growth early in the season.

The fact damage did not increase much with larval or adult density in the control efficacy test (experiment 1, Fig. 1), particularly given larval numbers were artificially maintained, suggests there is density dependence. The insect densities in both experiments also appear to be reaching saturation. Larval survival was not recorded, in the risk assessment test (experiment 2) but a similar number of larvae were found and a similar quantity of damage

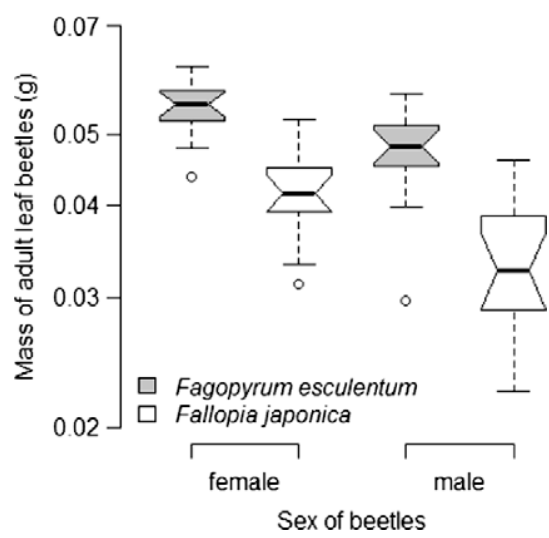

Fig. 4. The effect of host-plant on the mass of adult leaf-beetles. Adults were collected from the no-choice trials in experiment $2, n=15$ for each group. The bold lines show the median, the boxes the quartile ranges, and the lines show either 1.5 times the interquartile range or the point furthest from the median, whichever is less. Outliers outside this range are plotted individually. If the notches of two plots do not overlap, then the two medians are significantly different. 
was evident if two or four pairs of adults were added, although we cannot explain why the number of aestivating adults found both supported (in the choice tests) and did not support (in the nochoice tests) the hypothesis that density dependence is operating (Fig. 3).

We propose that larval density dependence in G. bifasciata operates via the availability of space for larvae and is contest in nature. Larvae feed and undergo four to five instars on the leaves. Apart from first-instar larvae, larvae appear to be limited in their ability to return to the plant if they fall off. Given there are limited numbers of suitable protected sites for larvae to moult and feed on $F$. japonica and that larval feeding might cause other larvae to fall off, we suspect, at least in the caged experimental systems here, that larval density dependence operates at this stage. There should also be little interference between adults and larvae, as adults tend to feed on leaves higher up on the plant, and winter synchronises the population such that it is usually univoltine. Therefore, the proposed larval density dependence is likely to be a major force in Wuhan and strongly stabilising.

Fallopia japonica reproduces from both seeds and vegetative regeneration of rhizomes and live stems. Results in this study indicate that, in response to above-ground herbivory, $F$. japonica was able to maintain large resources below-ground, probably allowing the plant to escape additional feeding damage and recover from herbivory. Therefore, a successful biological control programme against $F$. japonica probably requires both defoliators and rootfeeders to effectively suppress plant growth and reproduction. While there is a very promising leaf feeding agent from Japan, Aphalara itadori Shinji (Hemiptera: Psyllidae) (Shaw et al., 2009), surveys of insect natural enemies of $F$. japonica in its native range in China have failed to detect below-ground herbivores attacking rhizomes (J. Ding, unpublished). The response of rhizome growth to herbivory by defoliators, such as $G$. bifasciata, should be carefully considered when evaluating the efficacy of potential biological control agents.

As discussed previously, monitoring population dynamics of potential biological control agents on non-target weeds over an entire growing season in the native range can help predict indirect or direct non-target effects under more natural conditions (Ding et al., 2007; Louda, 1998; Louda et al., 2005). This study examined the adult and larval performance of $G$. bifasciata on both non-target (F. esculentum) and target ( $F$. japonica) plants over the complete active life-stages of $G$. bifasciata using a semi-field experiment. The results showed: (1) the leaf-beetle is able to complete its life cycle and sustain a population on $F$. esculentum during the growing season, but defoliation on this plant is less than on F. japonica; and (2) when $F$. esculentum grows with $F$. japonica, $G$. bifasciata will almost exclusively feed on $F$. japonica. Given the overlapping distribution of $F$. japonica and $F$. esculentum in North America (USDA, 2009), beetles dispersing into areas where only $F$. esculentum occurs might result in $F$. esculentum being colonized and defoliated.

It is interesting that the adults reared on $F$. esculentum in this study were heavier than those reared on F. japonica. However, a previous experiment discovered that G. bifasciata prefers to oviposit on F. japonica rather than $F$. esculentum (Wang et al., 2008). Adult oviposition on selected host-plants by phytophagous insects is usually positively correlated to larval performance (Jaenike, 1978; Rausher and Papaj, 1983; Ng, 1988; Thompson, 1988; Auerbach and Simberloff, 1989; Fox, 1993). However, some studies have documented adults feeding and ovipositing preferentially on hosts which provide inferior nutrition for their offspring (Mayhew, 1997; Scheirs et al., 2000). It might be that F. esculentum is a better nutritional resource for $G$. bifasciata, but $F$. japonica is more attractive for oviposition.

Host-selection by G. bifasciata has been shown to be affected by chemical cues. For example, (Z)- and (E)-11-eicosenyl acetate stim- ulates adults to feed and lay eggs (Matsuda and Sugawara, 1978), and 3-hydroxyl-5-methoxy-6,7-methylenedioxy flavanone acts as a larval feeding deterrent (Abe et al., 2007). Therefore, further chemical ecology studies might help elucidate the mechanisms involved in the host-selection of G. bifasciata.

Host-plant phenology is also known to affect insect host-selection in nature (How et al., 1993; Komatsu and Akimoto, 1995; Whipple et al., 2009), thus influencing the ecological host-range of biological control agents. This appears to be the case with $G$. bifasciata. In central China, seeds of $F$. esculentum are usually sown in late May or early June around the time adult G. bifasciata are aestivating, and so it is unsurprising that $G$. bifasciata is not known to attack $F$. esculentum in this area. However, we would expect the number of generations of $G$. bifasciata and the planting phenology of $F$. esculentum to vary across the invasive range of $F$. japonica in North America, and so we have to assume that in parts of the USA. G. bifasciata would be active at the same time as F. esculentum is being produced.

In this regard, it is important to note that, further southwest in China, a different race of $G$. bifasciata often uses $F$. esculentum as a host-plant ( $\mathrm{Li}$ and $\mathrm{Li}, 1994)$. The race used in the experiment also occurs there, but is much rarer and has not been found on F. esculentum to the best of our knowledge (Wang, unpublished). Further work needs to be done to elucidate the species complex and see if there are races more specific to $F$. japonica.

\section{Conclusions}

In summary, G. bifasciata causes significant levels of damage to F. japonica under both laboratory and semi-field conditions. We also propose a mechanism for population regulation that will be stabilising, and so expect $G$. bifasciata to be a suitable agent. However, F. japonica plants do survive leaf feeding by G. bifasciata, and plants could potentially show significant compensatory growth later in the season. Additional research on resource allocation is necessary when evaluating biological control agents of $F$. japonica.

We also show that, G. bifasciata can use $F$. esculentum as a host. The risk of non-target damage might be minimised if there is geographical and/or temporal separation between $F$. esculentum production and G. bifasciata activity, but this is impractical. Alternatively, more research on the $G$. bifasciata species complex might identify more host-specific races. However, the current population of G. bifasciata in Wuhan represents an unacceptable level of risk to F. esculentum in North America.

\section{Acknowledgments}

The project was funded by the USDA Forest Service, Forest Health Technology Enterprise Team, Morgantown, West Virginia, and we thank Richard Reardon for his support. We also thank, Wu Kai, Guo Wenfeng, Li Xiaoqiong and Guo Xiaohui for their field assistance. We thank Matthew Purcell, Raymond Carruthers and Matthew Jason Frye for their comments and suggestions that greatly improved earlier versions of the paper. We also thank Wang Yi for his valuable advice on our research.

\section{Appendix A. Supplementary data}

Supplementary data associated with this article can be found, in the online version, at doi:10.1016/j.biocontrol.2009.12.005.

\section{References}

Abe, M., Niizeki, M., Matsuda, K., 2007. A feeding deterrent from Persicaria lapathifolia (Polygonaceae) leaves to larvae of Gallerucida bifasciata (Coleoptera: Chrysomelidae). Applied Entomology and Zoology 42, 449-456. 
Auerbach, M., Simberloff, D., 1989. Oviposition site preference and larval mortality in a leaf-mining moth. Ecological Entomology 14, 131-140.

Bailey, J., 2003. Japanese knotweed s.l. at home and abroad: ecological threats and management solutions. In: Child, L.E. et al. (Eds.), Plant Invasions: Ecological Threats and Management Solutions. Backhuys, Leiden, The Netherlands, pp. 183-196.

Barney, J.N., 2006. North American history of two invasive plant species: phytogeographic distribution, dispersal vectors, and multiple introductions. Biological Invasions 8, 703-717.

Beerling, D.J., Bailey, J.P., Conolly, A.P., 1994. Fallopia japonica (Houtt.) Ronse Decraene. Journal of Ecology 82, 959-979.

Briese, D.T., 2005. Translating host-specificity test results into the real world: the need to harmonize the yin and yang of current testing procedures. Biological Control 35, 208-214.

Cameron, P., Walker, G., 1997. Host specificity of Cotesia rubecula and Cotesia plutellae, parasitoids of white butterfly and diamondback moth. Lincoln Univ. Canterbury, New Zealand, New Zealand Plant Protection Soc., Forest Research Inst., Private Bag.

Ding, J., Wang, Y., Jin, X., 2007. Monitoring populations of Galerucella birmanica (Coleoptera: Chrysomelidae) on Brasenia schreberi and Trapa natans (Lythraceae): implications for biological control. Biological Control 43, 71-77.

van Driesche, R.G., Blossey, B., Hoddle, M., Lyon, S., Reardon, R., 2002. Biological Control of Invasive Plants in the Eastern United States. Forest Health Technology Enterprise Team Morgantown, West Virginia. pp. 159-166.

Fox, C.W., 1993. A quantitative genetic analysis of oviposition preference and larval performance on two hosts in the bruchid beetle, Callosobruchus maculatus. Evolution 47, 166-175.

Haye, T., Goulet, H., Mason, P.G., Kuhlmann, U., 2005. Does fundamental host range match ecological host range? A retrospective case study of a Lygus plant bug parasitoid. Biological Control 35, 55-67.

How, S.T., Abrahamson, W.G., Craig, T.P., 1993. Role of host-plant phenology in host use by eurosta-solidaginis (diptera, tephritidae) on solidago (compositae). Environmental Entomology 22, 388-396.

Jaenike, J., 1978. On optimal oviposition behaviour in phytophagous insects. Theoretical Population Biology 14, 350-356.

Komatsu, T., Akimoto, S., 1995. Genetic differentiation as a result of adaptation to the phenologies of individual host trees in the galling aphid Kaltenbachiella japonica. Ecological Entomology 20, 33-42.

Li, W., Li, F., 1994. Biology and research of control of Gallerucida bifasciata Motschulsky. Entomological Knowledge 31 (5), 273-275.

Louda, S.M., 1998. Population growth of Rhinocyllus conicus (Coleoptera: Curculionidae) on two species of native thistles in Prairie. Environmental Entomology 27, 834-841.

Louda, S.M., Rand, T.A., Russell, F.L., Arnett, A.E., 2005. Assessment of ecological risks in weed biocontrol: input from retrospective ecological analyses. Biological Control 35, 253-264.
Maerz, J.C., Blossey, B., Nuzzo, V., 2005. Green frogs show reduced foraging success in habitats invaded by Japanese knotweed. Biodiversity and Conservation 14 2901-2911.

Matsuda, K., Sugawara, F., 1978. Feeding stimulants of the beetles attacking the Polygonaceous plants. Tohoku Journal of Agricultural Research 29, 120-122.

Mayhew, P.J., 1997. Adaptive patterns of host-plant selection by phytophagouse insects. Oikos 79, 417-428.

McClay, A.S., Balciunas, J.K., 2005. The role of pre-release efficacy assessment in selecting classical biological control agents for weeds-applying the Anna Karenina principle. Biological Control 35, 197-207.

Morehead, S.A., Feener, D.H., 2000. An experimental test of potential host range in the ant parasitoid Apocephalus paraponerae. Ecological Entomology 25, 332340.

$\mathrm{Ng}, \mathrm{D} ., 1988$. A novel level of interactions in plant-insect systems. Nature 334, 611 612.

Pearson, D.E., Callaway, R.M., 2003. Indirect effects of host-specific biological control agents. Trends in Ecology and Evolution 18, 456-461.

Rausher, M.D., Papaj, D.J., 1983. Demographic consequences of discrimination among conspecific hostplants by Bauus philenor. Ecology 64, 1402-1410.

Scheirs, J., De Bruyn, L., Verhagen, R., 2000. Optimization of adult performance determines host choice in a grass miner. Proceeding of the Royal Society of London Biological Sciences 267, 2065-2069.

Sheppard, A.W., van Klinken, R.D., Heard, T.A., 2005. Scientific advances in the analysis of direct risks of weed biological control agents to nontarget plants. Biological Control 35, 215-226.

Shaw, R.H., Bryner, S., Tanner, R., 2009. The life history and host range of the Japanese knotweed psyllid, Aphalara itadori Shinji: potentially the first classical biological weed control agent for the European Union. Biological Control 49 105-113.

Thompson, J.N., 1988. Evolutionary ecology of the relationship between oviposition preference and performance of offspring in phytophagous insects. Entomologia Experimentalis Applicata 47, 3-14.

USDA, 2009. Global Biodiversity Information Facility.

Wang, Y., Ding, J., Zhang, G., 2008. Gallerucida bifasciata (Coleoptera: Chrysomelidae), a potential biological control agent for Japanese knotweed (Fallopia japonica). Biocontrol Science and Technology 18, 59-74.

Wilson, J.R.U., Rees, M., Ajuonu, O., 2006. Population regulation of a classical biological control agent: larval density dependence in Neochetina eichhorniae (Coleoptera: Curculionidae), a biological control agent of water hyacinth Eichhornia crassipes. Bulletin of Entomological Research 96, 145-152.

Whipple, A.V., Abrahamson, W.G., Khamiss, M.A., Heinrich, P.L., Urian, A.G. Northridge, E.M., 2009. Host-race formation: promoted by phenology, constrained by heritability. Journal of Evolutionary Biology 22, 793-804. 